\title{
Research
}

\section{Mismatch Between Scales of Knowledge in Nepalese Forestry: Epistemology, Power, and Policy Implications}

\author{
Helene Ahlborg ${ }^{1}$ and Andrea J. Nightingale ${ }^{2,3}$
}

\begin{abstract}
The importance of scale dynamics and scale mismatches for outcomes of natural resource management has been widely discussed. In this article we develop theoretically the concept of 'knowledge scales' and illustrate it through empirical examples. We define scales of knowledge as the temporal and spatial extent and character of knowledge held by individuals and collectives, and argue that disparate scales of knowledge are an important 'scale mismatch,' which together with scale politics, lead to conflicts in Nepalese forest management. We reveal how there are multiple positions within local knowledge systems and how these positions emerge through people's use of and relations to the forest, in a dynamic interaction between the natural environment and relations of power such as gender, literacy, and caste. Nepalese forestry is a realm in which power and scales of knowledge are being coproduced in community forestry, at the interface of material and symbolic practices in use of forest resources, and in contestations of social-political relations. Further, we reflect upon the importance of clear and precise use of scale concepts and present a methodological approach using triangulation for divergence, enabling researchers and practitioners involved in natural resource management to reveal scale mismatches and politics.
\end{abstract}

Key Words: community forestry; knowledge scales; natural resource management; Nepal; power; scale

\section{INTRODUCTION}

The need to tackle global challenges at the societyenvironment interface has brought with it concerns over the complex dynamics between ecological, social, and political processes across various temporal and spatial scales (Cash et al. 2006, Cumming et al. 2006, Termeer et al. 2010). However, scale is not simply a problem of resolution or extent. Rather, a fundamental problem for natural resource management (NRM) is that the resource in question can be understood differently depending on the temporal and spatial scales of observation. The choice of scale mirrors the knowledge culture and priorities of the observer, it influences what can be seen and the conclusions made, and therefore scale itself requires scrutiny (Gibson et al. 2000, Sheppard and McMaster 2003, O'Flaherty et al. 2008, Rangan and Kull 2009). In this paper we argue that the choice of observational scale, i.e., the temporal, spatial, or quantitative dimensions used by scientists to measure and study the world, has policy implications and is part of how power is exercised in natural resource management. Many scholars are well aware that the choice of observational scale is not neutral. Such awareness of the political implications of scale choices have led to use of multiscale assessments, to increase the credibility and relevance of findings. However, in this article, we take these ideas a step further, and develop a theoretical argument about 'knowledge scales', drawing upon Nightingale's case study results from Nepalese forestry $(2001,2003,2005,2006,2010)$ to illustrate the ways that different temporal and spatial scales of knowledge become part of the emergence of power and ecological change in social-ecological systems.
Forestry in Nepal is home to scale mismatches between social, ecological, and political processes. However, it is also an arena for conflicts between and within different knowledge systems, with important implications for policy. We argue that disparate scales of knowledge are an important 'scale mismatch,' which together with scale politics, including scale-dependent interests in resources and ecosystem services (Lebel 2006), lead to conflicts in Nepalese forest management. There are multiple positions within local knowledge systems, and these positions emerge through people's use of and relations to the forest, animated by a dynamic interaction between the natural environment and power relations such as gender, literacy, and caste (Nightingale 2005). Nepalese forestry is therefore a realm in which scientific and local knowledge systems meet on unequal footing, but also where less visible conflicts and scale mismatches are found. We demonstrate how such mismatches and conflicts can be revealed and illuminated through the use of mixed methods that both (a) employ multiple observational scales and (b) allow triangulation for divergence, that can reveal the silences and gaps between data sets and give equal weight to different knowledge systems.

Our aim is thus to (1) interrogate the problem of mismatch between scales of knowledge in natural resource management, (2) illustrate how scale politics and mismatch take place both between and within knowledge systems in Nepal, and (3) discuss the implications for methodological approaches and methods. We define knowledge scales/scales of knowledge as the temporal and spatial extent and character of knowledge held by individuals and collectives. We develop this concept theoretically, and using the example of community forestry in

\footnotetext{
${ }^{1}$ Environmental Systems Analysis, Chalmers University of Technology, ${ }^{2}$ Institute of Geography and the Lived Environment, School of GeoSciences, University of Edinburgh, ${ }^{3}$ School of Global Studies, University of Gothenburgh
} 
Nepal, illustrate how actors' understanding of the forest is strongly related to: (a) different needs, interests, and values, and also (b) knowledge derived from multiple temporal and spatial scales. As a result, actors interpret both the forest and the rationale of forest management through specific, and often conflicting, frames.

Our discussion of scale concepts takes place in the context of society-nature interactions, or social-ecological systems (SES). Our purpose is to build a bridge between understandings of scale in the social and ecological sciences, capitalizing on our backgrounds in human geography and environmental science. This article is the result of insights made through joint discussion on empirical findings from Nightingale's (2001, 2003, 2005, 2006, 2010) work on forestry, in parallel with theoretical engagement of scale concepts across disciplines. To support our argument, we critically review conceptualizations of scale and scale mismatch, and then discuss the epistemological dimension, i. e., the mismatch between scales of knowledge, illustrated through analyses of our previous empirical work.

\section{SCALE AND LEVEL IN ECOLOGY AND GEOGRAPHY}

Scale has been conceptualized in many disciplines (Peterson and Parker 1998, Gibson et al. 2000, Sheppard and McMaster 2003, Manson 2008, Rangan and Kull 2009, Termeer et al. 2010) and is a key concept in both geography and ecological science, where it has long been considered a fundamental problem (Levin 1992). To understand the use of scale concepts in natural resource management, we make two key distinctions: (1) between scale and level and, (2) between scale as pre-existing, and scale as constructed. We discuss these distinctions and clarify our use of scale.

In ecological science, scale is defined as the physical dimensions of observed entities and phenomena, which is usually recorded as a quantity, e.g., spatial extent and temporal duration, and involves or at least implies measurement and measurement units (O'Neill and King 1998, Reid et al. 2006). Importantly, scale is different from the concept of level although these are often conflated and treated as synonyms (O’Neill and King 1998). Level can be understood as locations along a scale (Gibson et al. 2000), which in a hierarchical system refers to levels of organization, characterized by the rate of a process (O'Neill and King 1998). In ecology, lower levels often have faster rates and higher levels often have slower rates of change, e.g., cellular processes vs. those of an organism as a whole. Level of organization is a relative characterization of system organization, or as Allen (1998) calls it, "definitional," i.e., relationships that derive from definitions employed by the observer, or "what people accept it to be" (Reid et al. 2006:7-8). There are different possible ordering principles that have theoretical implications. Traditional levels used by ecologists are organism, population, ecosystem, landscape, and biome but these levels have proven to be problematic and arbitrary concepts, especially when used as a priori theoretical constructs (O'Neill and King 1998). The confusion of scale and level is common in the literature, one reason being that the rate of a process that defines a specific level also has a temporal and spatial scale over which that process operates (O'Neill and King 1998), e.g., a specific organism (level) has a certain body size and lifespan (scale).

Conceptual confusion may also stem from differences between ecological and social systems, such as when the temporal rates of processes at various levels in social hierarchies are not necessarily ordered like rates in ecological hierarchies (Wilbanks 2006). For example, although the rates of microlevel processes in the cell are faster than macrolevel processes in populations, temporal rates of human life (microlevel) follow stable patterns at the individual and family level, but governments (macrolevel) may rise and fall over weeks, months, years, or decades.

To further muddy the conceptual distinctions between scale and level, they are often used in imprecise ways, or different applications can be because of different epistemological positions, ranging from realist to constructionist perspectives (Manson 2008). Realist ideas of scale and level assume these to pre-exist, as part of how the world is naturally ordered. This is how the concepts are most often used in environmental science and by many SES researchers.

However, challenges to realist conceptions of scale have come from both the social and ecological sciences. Scale is not a thing 'out there' to discover (Allen 1998), it is the physical dimensions of things we observe as framed by the observer. There are objects, biological entities, and processes in nature that exist independently of human observations and these have spatiotemporal relationships that cannot be changed at will, but how we choose to measure them is not absolute. In other words, scales are agreed upon measures, e.g., millimeters, kilometers, seconds, hours, that exist in the minds of observers, and as such are social constructions, yet they are also abstractions of proportional relationships in nature, and thus have a physical basis to them. Scale, however, "becomes meaningful with regard to things only when it is operationalized in its use in a measure in the act of observation" (Allen 1998:37). Scale is therefore linked to what is observed in the world (Allen 1998), yet it is equally linked to how we observe the world and our dominant epistemological conceptions that help us to make sense of what we see (Berger 1972, Lewontin 1991).

These distinctions between 'what is out there' and what is 'socially constructed' bring us firmly into the realm of epistemology, where geographers have been at the forefront of conceptualizing scale. Many human geographers have argued that scale is socially constructed and thus, and this is an insight relevant also for ecologists, inherently political 
(Herod and Wright 2002, Sheppard and McMaster 2003). Scale and level are defined in the act of ordering the world, whether that be in terms of assigning a priori organizational levels in biology, i.e., cell, organism, population, or in framing social issues as taking place at the global scale. Also of crucial importance to our argument is the idea that how we see the world is not neutral, but rather is bound up in our histories, geographies, and the politics of knowledge production (Livingstone and Withers 1999). We argue, therefore, that although scale is not arbitrary (it is defined based on relationships that are more or less immutable), how scale is framed and which scales and levels are prioritized in research are political choices. As such it requires researchers to be reflexive about the politics inherent in their work.

Empirical and cross-disciplinary studies of SES have further helped to broaden the understanding of scale concepts, although in general, people working in this field have not taken up the challenge we present here. There are now a number of uses and definitions, complementing the traditional temporal and spatial scales, such as institutional, jurisdictional, knowledge, and management scales (for a review see Termeer et al. 2010). We find these broader applications of the scale concept interesting, so the point here is not to say which one is best. However, we are cautious of the conflation of disparate ideas that can result, especially from the confusion of scale and level. To give an example of how a definition of scale that distinguishes from level is useful in this domain, we refer to jurisdictional scales as the spatial extent of a jurisdiction (the area under jurisdiction) but also include its size, in terms of number of people; although we use level to refer to organizational levels of jurisdiction, e.g., national authorities, courts, municipalities, etcetera.

In sum, it is possible to bring together understandings of scale in ecological science and human geography by clear and precise use of concepts. There is need for conceptual clarity to avoid misunderstandings when we communicate across disciplines, therefore we maintain that scale is preferably used to refer to dimensions of time, space, or quantity, or the scale of observation, i.e., the "spatial, temporal, quantitative, or analytical dimensions used by scientists to measure and study objects and processes" (Gibson et al. 2000:219), recognizing that these are socially framed. We add that these dimensions are not politically neutral, but rather the choice of scale and level requires scrutiny.

\section{SCALE MISMATCH IN FORESTRY AND SCALES OF KNOWLEDGE}

We have so far argued that the process of defining scale and level is at least in part linked to social processes, and thus following human geographers, the choice of scale in research is inherently political. However, these issues become even trickier when the scales of ecological and societal processes do not coincide, what is often known as 'scale mismatch'
(MEA 2005). We discuss scale mismatch and introduce the idea of knowledge scales, which we argue is another, underexplored dimension of scale mismatch.

The SES literature has contributed much to our understanding of cross-level and cross-scale dynamics and scale mismatches (Peterson and Parker 1998, Cash et al. 2006, Cumming et al. 2006, Folke 2006, Ostrom 2009, van Lieshout et al. 2011). As Cumming et. al. (2006:16) elaborate:

... scale mismatches occur when the scale of
environmental variation and the scale of the social
organization responsible for management are
aligned in such a way that one or more functions of
the social-ecological system are disrupted,
inefficiencies occur, and/or important components
of the system are lost.

Forestry starkly reveals a number of scale mismatches (Papaik et al. 2008). The slow growth of a forest and diverse forest ecosystem requires time spans longer than human life spans. Meanwhile, our societies and economies generally prioritize immediate needs and short-term gains, whereas monitoring forest change requires the ability to measure slow changes and delays in impacts. There is also often mismatch between the spatial distribution of forest ecosystems and the political and jurisdictional areas of forest management and use. Cross-level interactions between, for example, local user associations, district authorities, and national ministries of land, forest, agriculture, and multiple uses of forest resources add to the complexity (O'Flaherty et al. 2008, Papaik et al. 2008).

However, our point is that the problem of scale mismatch in forestry goes deeper than this. There is a more subtle, but equally important dimension of scale-mismatch that affects the frames for negotiation, rationality, and goals in NRM. It is the epistemological dimension, what we call knowledge scales, that relates to knowledge and worldview. Scales of knowledge refers to the spatial and temporal extent and character of knowledge held by individuals or collectives, public or scientific, not to be confused with the knowledge content per se, or with the organizational level at which stakeholders expressing that knowledge are active. Scales of knowledge is broader, and includes observational scale, as it applies to everyday life and scientific studies, as well as the scale at which actors frame and present their knowledge. As our case will illustrate, different scales of knowledge interact with contestations of power in Nepalese forestry, shaping actors' perceptions.

Quite often, scientific knowledge and local ecological knowledge are said to be in conflict. A knowledge system has been defined as a body of propositions adhered to that are routinely used to claim truth (Reid et al. 2006). Western science is one such knowledge system with its norms and procedures for 'truth-making' through a process of validating, 
abstracting, and generalizing knowledge. In contrast, local knowledge is seen as embedded in people and institutions and characterized as being contextual and applied (Agrawal 2002). Traditional ecological knowledge is according to Berkes and Folke (1998:8) a "cumulative body of knowledge, practice and beliefs, evolving by adaptive processes and handed down through generations by cultural transmission." It may or may not be indigenous, but "has roots firmly in the past" (Reid et al. 2006:11). Local knowledge is then referring to place-based experiential knowledge, oral and practice-based, as opposed to formal education. These cumulative 'bodies' of knowledge evolve over time and individuals may very well accept some parts and question others. To a certain extent, differing scales of knowledge help explain conflicts between how disparate knowledge systems understand social-ecological processes (see e.g., Bassett and Zuéli 2000, O'Flaherty et al. 2008).

Work on scale in forestry has argued that it is necessary to understand not only "... cultural differences between local communities and broader-scale society, but also the scales of perception and differences in the depth and character of knowledge associated with stakeholders at these different social levels" (Papaik et al. 2008:32-33). This is a very important insight but it does not go far enough. Rather, we explore how actors at various levels have differing interests and knowledge systems relating to forest resources and ecosystem services, yet we argue that knowledge held by all actors is inherently multiscalar, even if the interests of different actors are often scale-dependent (Lebel 2006). In our Nepalese case, we can see that the temporal and spatial scales of local knowledge systems differ both for actors within communities and from the 'expert' knowledge that forestry officials promote, but both of these knowledge systems are multiscalar.

Although much has been written on the relation between science and other knowledge systems (Latour 1987, Longino 1990, Agrawal 1995), we would like to bring into focus the heterogeneity of so called local traditional knowledge as well as the differing scales of knowledge within local communities, resulting in unconscious mismatches between knowledge scales, communication problems, lack of legitimacy, and some local knowledge being ignored or devalued. We will further develop the implications of scale choices as they manifest in encounters between different knowledge systems and discuss the use of multiscale assessments as a response to the challenges posed by scale of observation.

\section{SCALES OF OBSERVATION AND MULTISCALE ASSESSMENTS}

The above analysis points to how scale choices are fundamental to how scientific knowledge is produced. From an epistemological point of view, scale of observation is about the limits of knowledge. When we observe the environment, we necessarily do so within a limited range of scales; therefore, our perceptions of events will be limited. The choice of observational scale mirrors the knowledge culture and priorities of the scientist, it influences what can be seen and the conclusions made (Reid et al. 2006, O'Flaherty et al. 2008, Buizer et al. 2011). It may be deliberately chosen by researchers to highlight specific features, although at other times it is for practical or logistical reasons (Levin 1992), and it may also be taken for granted; regardless, the choice of scale has implications. Philosophical debates on epistemology have created an awareness of the plurality of knowledge systems and the impossibility of "context-free or super-cultural norms of rationality" (Barnes and Bloor 1982:27). The contributions from sociology of science (Latour 1987), feminist critiques of science (Haraway 1991), the works of Kuhn (1962/1970) and Foucault (1980) among others have created debates for reflexivity on and acknowledgement of the normative underpinnings in how we do science.

In environmental assessments, there is a politics of scale acting on the framing, conducting, and use of an assessment with implications for how problems are outlined and who is identified as a stakeholder (Lebel 2006). According to Rangan and Kull (2009), the preconceived ideas held by social and natural scientists on ecological change influence the delineation of a system, which plays a crucial role in determining the outcome of change, and by including some and excluding other aspects and actors (Lebel 2006, Wilbanks 2006). Rangan and Kull (2009) see scale as the means by which ecological change becomes political. According to them, scale is produced in words like transformation, degradation, or evolution, good, bad, alien, invasive, native, or benign, words and concepts used to explain or argue for or against the processes and outcomes of ecological change. Scale of observation is also inherently political because ecological assessments of cross-scale processes that give precedence to expert knowledge may discriminate against indigenous, local knowledge, minorities, or marginalized groups (MEA 2005, Reid et al. 2006, Termeer et al. 2010).

In ecology, scale of observation has also received much critical attention. Ecologists often talk about the 'characteristic' scale of ecosystem processes and services, i.e., the typical extent or duration over which processes have their impact (MEA 2005), but this should not be taken as saying that there is a correct scale of observation (O'Neill and King 1998, Cash et al. 2006, Termeer et al. 2010). As Levin (1992:1947) writes, “... the problem is not to choose the correct scale of description, but rather to recognize that change is taking place on many scales at the same time, and that it is the interaction among phenomena on different scales that must occupy our attention." O'Neill and King (1998:6) write, “... if you move far enough across scale, the dominant processes change. It is not just that things get bigger or smaller, but the phenomena themselves change. Unstable systems now seem stable. Bottom-up control turns into top-down control.” 
Moving between scales is a trade-off between detail of variation and statistical predictability. According to Levin (1992), this makes it clear that there are no natural levels of description, although some scales are more appropriate to study phenomena than others. This is a crucial point, and we adhere to the idea that some scales are more appropriate than others for scientific study of phenomena, however, we also argue that scientists need to reflect upon the policy implications of their scale choices and the trade-offs coming with them.

As a way to deal with the limitations and biases imposed by the scale of observation, studies in ecology, common property, and related SES work agree that there is need for multiscale assessments and cross-scale studies (Levin 1992, O'Neill and King 1998, MEA 2005, Allen and Holling 2010). According to the Millennium Ecosystem Assessment (MEA) report on multiscale assessments, "an effective assessment of ecosystems or human well-being cannot be conducted at single temporal or spatial scales" (MEA 2005:23). The motivation behind this statement is that single scales are too limited and risk misinterpreting results.

The use of multiscale assessments thus potentially has two types of benefits: information benefits and impact benefits. First, multiple scales might improve accuracy, validity, or applicability of findings (MEA 2005). For example, scholars propose that local knowledge should complement scientific knowledge (Reid et al. 2006, O'Flaherty et al. 2008, Gagnon and Berteaux 2009). Thus, in a Canadian study on Inuit traditional ecological knowledge and scientific knowledge about the arctic fox and greater snow goose in the tundra, Gagnon and Berteaux (2009) see traditional and scientific knowledge as complementary, increasing the temporal extent and adding more spatial scales to combined knowledge, thereby increasing validity of results. The impact benefits of multiscale assessments are considered to increase the relevance, ownership, credibility, and legitimacy of results for all stakeholders involved (MEA 2005, Reid et al. 2006). Local assessments, for example, may lead to recommendations about societal response that require action at national levels but find these actors unwilling to respond. Similarly, global scale ecosystem assessments may lack credibility and relevance for local actors in areas where action is needed (MEA 2005, Ostrom 2009).

However, this kind of framing of cross scale and multiscalar assessments conflates the level at which knowledge is expressed or mobilized with the scale of knowledge. The MEA suggests that local knowledge is important to include, but the assumption is that at a (defined) local level, there is knowledge that is specific and identifiable, rather than recognizing that the framing of local is itself linked to (often contested) processes that produce hierarchical relationships among knowledge systems. Local knowledge is not limited to local scales of knowledge, but rather involves multiple time frames and geographical scales and is embedded within other systems of knowledge, especially science; it is the level of the actors and the ecosystems that are local. Much science is both contextual and based on local scales of observation, making the process of abstraction and generalization carry a risk of improper applications in other contexts (see also Hulme 2010 for a critique of the geographical spread of the Intergovernmental Panel on Climate Change expertise). Science and other knowledge systems remain distinct, however, in that they are still unequal in terms of legitimacy, political influence, and economic power (Lebel 2006).

Multiscale assessments in themselves do not remove the issue of scale politics in ecosystem assessments because strategic interests and powerful actors will still try to promote their agenda. In the Nepal forestry example, we show how local knowledge is in fact multiscalar and differentiated. We argue, therefore, that assuming that local knowledge circulates and exists on that level is political in itself and requires interrogation.

In sum, we see the choice of observational scale by researchers, because of habit, determined by standard methodological packages or practical circumstances, as part of the process of creating preferential rights of interpretation and legitimacy for certain actors, perspectives, and policies. Among local actors there is both a politics of scale that arises, e.g., in terms of making knowledge claims by referring to western science, and differences in scales of knowledge that shape the local responses to NRM and policy. Seeing local, traditional, or indigenous knowledge as complementary to science is important but simultaneously strengthens the idea of separate systems, and risks overlooking the differences within communities and between local knowledge systems. We use examples from Nepalese forestry to show how scale is produced and politicized when more powerful actors frame the problem and the vision of the forest in a way that sometimes conflicts with the visions and needs of the less privileged groups in society. It matters both for ecological outcomes in that conflicts over knowledge and power are often 'acted out' on the ground as violations of harvesting rules, etcetera, and for the ways that scale is produced and politicized, which reshapes or even undermines local knowledge systems.

\section{MIXED METHODS AND TRIANGULATION FOR DIVERGENCE}

The following examples are based on data gathered in Nepal since 1993 by Nightingale, using a combination of quantitative and qualitative methods. Specifically we refer to the analyzed results of data collected using participant observation, in-depth qualitative interviews, a community and land use census, aerial photo interpretation, and a forest vegetation inventory. These methods were used over two periods of fieldwork in 1993-1994 and 1999 (a total of 12 months) to understand the 
social-ecological dynamics of community forestry management. The data from each method was analyzed separately, using standard validation techniques and triangulation for convergence where appropriate, i.e., between the aerial photos and vegetation inventory, or the participant observation and the interviews (Nightingale 2001). It should be noted, however, that the results of each of these data sets were treated as equally valid and a key goal of the research was to interrogate how knowledge about forestry is produced (Nightingale 2003). Thus, these data sets were then analyzed by triangulation for divergence.

Triangulation of data is most often used for validation of results by convergence; however, there are two other less common approaches to triangulation: triangulation for complementarity (Huntington et al. 2004, Gagnon and Berteaux 2009) and triangulation for divergence, where data sets do not match. Divergence as an approach analyzes not only for complementarity, but also examines the partiality of knowledge and helps to reveal the mismatches between scales of knowledge of the actors, i.e., scientists, government officials, and citizens, involved. Our primary focus here is on scales of knowledge. A mapping of all the ways the politics of scale are being played out by various actors is outside the scope of this paper. We have updated the results from the earlier field work with analyses of the most recent policy developments in Nepal.

\section{COMMUNITY FORESTRY IN NEPAL: SCALE MISMATCH AND THE KNOWLEDGE SCALES}

Forestry programs in Nepal are considered some of the most progressive in the world, with several different types of decentralized, participatory programs giving control over management to village users (Ojha et al. 2008). Community forestry (CF) is the largest and most well-established of these programs and is often upheld as a global model of successful, participatory resource management.

Recently, questions of knowledge and observational scale have moved to center stage in Nepalese forestry debates. Climate change in the Himalayas is projected to be some of the most severe globally, causing significant changes in glacial runoff, rainfall, and temperature (Duan et al. 2006, Xu et al. 2009). Given these predictions and as a least developed country, Nepal has been targeted for pioneering carbon adaptation and mitigation programs such as Reducing Emissions from Deforestation and Degradation (REDD+). REDD+ is a mechanism to allow developing countries to sell carbon credits generated from forest conservation programs. In Nepal, a coalition of actors has been working to try to distribute potential revenue from this program to individual community forest user groups. The desire to bring direct benefits to the ordinary people widely believed to be most responsible for the tremendous gains made in forest cover over the past 30 years is laudable, but throws into relief scale issues.
To understand the challenges posed by current climate change concerns, we will first illustrate how mismatch between scales of knowledge and scale politics have played out in the past.

The development of CF in Nepal, beginning in the 1980s and gaining momentum after 1990, quickly became a program wherein scientific 'expert knowledge' was given priority over local knowledge systems. This development took place through a set of organizational, symbolic, and material practices embedded in existing power relations (Ojha 2008) clearly seen in the process of constituting a group. To take over the management of a community forest, a user group must first map the forest and develop an operational plan (Shrestha et al. 1995). Ideally, the District Forest Office (DFO) staff and, where relevant, foreign-donor project staff, provide substantial assistance to user groups during this phase, although in practice the support given is variable. Once the forest has been roughly surveyed, the boundaries mapped, and the operational plan approved, the government continues to legally own the land but villagers have the right to manage, use, and sell all forest products (Government of Nepal 1995). Development practitioners in community forestry programs promote the diffusion of knowledge to local people with an underlying assumption that ordinary villagers are 'backwards' and need to be 'sensitized' to proper forest management and more recently, climate change. Knowledge is understood as professional/expert knowledge, and something different from local traditional knowledge (Nightingale 2005). In many respects, the promotion of professional knowledge sits at the core of decentralization goals.

Decentralization in this context is based on the idea that common resources need to be privatized and regulated through collective management. Such property arrangements assume the existence of a recognizable and uncontestable local community that can control and manage the forest (Zimmerer 2000, Nightingale 2005). For people to be legitimate managers of the forest, they need to be trained by officials and gain the 'right' type of knowledge. The maps and operational plans required to constitute a community forest user group thus take on significance beyond simple management documents. They become symbols of 'professional' forestry and scientific knowledge and as such are strategically used by local actors to control resources (Nightingale 2005). In Mugu district, knowledge claims intersect with power relations within user groups such that literate, high caste, usually male members, who rarely work in the forest because it is seen as low caste work, use their superior abilities to read, interpret, and 'understand' these documents to assert their right to control the group (see also Thoms 2008). Meanwhile, the knowledge of illiterate, usually lower caste and female members is marginalized.

The management plans and maps are based on different, and fewer, temporal and spatial scales than knowledge held by 
local users. The map represents a detached position, at a larger spatial scale and without the detail of local conditions on the ground (Rocheleau 1995, St. Martin 2005). Although on the one hand such a simplified, detached position is the whole point of a map (by necessity choices are made about what to include or not) our concern here is with the way the map can be given preference over other ways of representing the forest when disputes arise. Management rules are based on general knowledge gained in other contexts, usually from monoculture forestry for timber production rather than multiuse forestry. Monoculture forestry does not provide the biodiversity required for multiuse forests that are currently needed for sustainable rural livelihoods in Nepal. Despite this, industrial forestry guidelines are given priority over local knowledge systems. As a result, CF becomes a terrain wherein the scale of forestry management both in terms of knowledge and social organization is produced and rescaled to the interests of the local elite. Within the local community, people with more everyday and hereditary experience of the forest are dismissed as illiterate and ignorant, while high caste men who do not work in the forest claim to be the ones knowledgeable (see also Khadka 2010).

Scientific representations of forest change, e.g., remote sensed data, are becoming increasingly dominant for determining changes in forest cover, land use, and environmental degradation because they are seen to be more reproducible and generalizable and thus comparisons across regions of the world are easier (Nightingale 2010). These developments have implications both in terms of the quality of information and the credibility and legitimacy of different knowledge systems for forest policy, a trend which is compounded by concerns over climate change in the Himalayas. Ignoring the mismatch between scientific scales of observation and the scales of knowledge mobilized by local actors may lead to misinterpretation of results, misdirected policy, and conflicts between stakeholders. CF user groups are well aware of changes occurring in their environment even if they do not cast such knowledge in the language of 'climate change.' As one donor-supported user group member said after listening to a radio program on climate change:

In earlier times, I used to hear the news about
drought after hail, hunger problems, firebreaks, and
sometimesfloods. But now, I find less rain, and there
is change in the timing of rain too. The days are
becoming hotter and hotter. Water flow level is also
decreasing in rivers and streams... 65 year old man,
western hill district (quote courtesy of the
Livelihoods and Forestry Programme Kathmandu)

Programs like those on the radio and the Livelihoods and Forestry Programme's (LFP) Climate Adaptation Planning initiative are rapidly spreading 'knowledge' about climate change into the far flung villages of rural Nepal, but although this may bring some common vocabulary, it does not fundamentally resolve the tensions related to differing interest, scales of knowledge, and problem understanding. Rather, villagers are concerned about particular water sources drying up, changes in understory grazing species in their forest, while the government and international donors at the global level are concerned about whether the geographic distribution of forest ecotypes, i.e., valuable hard wood 'Sal' forests vs. lower value coniferous forests, will change, or if wide spread food insecurity will result from changes in rainfall and vegetation types.

To interrogate and tackle scale mismatches, we suggest the use of mixed methods (qualitative and quantitative) to explore the gaps between different knowledge systems (Nightingale 2003). In Mugu District, Nightingale used qualitative ecological oral histories to assess landscape change from the perspective of local people. The oral histories were based on 65 in-depth interviews with local people, using theoretical saturation, i.e., asking the same questions to different people until you get no new information, and participant observation (about 12 months total 1993-1994, 1997, 1999) for tests of reliability and validity (complete results available in Nightingale 2001, 2003, 2005, 2006, 2010). Most people when asked about how the forest had changed during their life time, told stories of thick and wild forests, controlled by the village headman, that dominated many parts of the valley during their childhood, roughly 35-60 years ago. In the 1970s, however, the district forest office (DFO) took over management and according to these narratives, ecological conditions rapidly declined. After forest management was returned to the village through the community forestry in 1991, people were adamant ecological conditions improved, increasing their access to firewood, timber, and leaf litter.

A quantitative analysis based on an aerial photo time series (1978-1996), providing snapshots of land cover change at a resolution of 1:50,000, was combined with a vegetation inventory sampling $5 \%$ of the area (complete results available at Nightingale 2001, 2003). The vegetation inventory was triangulated with data from aerial photo imagery and this combined analysis produced an internally valid data set, but one that told a different story about forest change. A slight increase in forest cover could be seen overall, with most improvement evident close to the villages (Nightingale 2003, 2010). When these findings were triangulated with the interviews, which showed divergent results, it was possible to draw conclusions about the relative importance of different parts of the forest, and to understand how the villagers' understandings of forest change were based on different criteria than simply total forest cover. Areas that are most accessible to local people had improved the most, helping to explain people's positive responses. However, this conclusion emerges from the gaps between data sets; when asked about the forest, people emphasized that the whole forest was important to them (Nightingale 2003). 
These examples illustrate how the forest and its problems are understood differently by actors at different levels, and also within local communities. Such differences emerge in part from the forest ideal they envision and the temporal and spatial scales of their knowledge. Forest officials see monoculture stands for timber as the main resource, and base their expert recommendations on generalized scientific knowledge extracted from other geographical places and periods in time, and data from satellite imagery, maps, and ecological surveys. However, local people's knowledge about the forest spans multiple time frames, based on people's life-long relation to it, the daily and seasonal harvesting of various forest resources, and the oral knowledge and symbolic meaning traded from older generations, as well as their interactions with forestry officials and forestry 'science.' Spatially, the local forest is discontinuous or network-like: the forest signifies the nearby tree stands, key places in the forest where certain resources are found, "wild" forest where people do not go, sacred spaces, and places of local historical reference, the routes for travel, areas that are seen as natural borders to neighboring villages, but also the area under local control, and areas under the jurisdiction of the district authorities (Nightingale 2010).

Finally, the forest also signifies the dynamic social and political relations villagers have with each other and to external actors. The forest is differentially accessible temporally and spatially for women and men, rich and poor, high and low caste (Nightingale 2003). In saying that the forest has improved with community forestry, people refer to changes both in forest cover and social-political relations that are seen as positive. Thus, when people oppose community forestry, they may do so because their interests and knowledge are being disregarded. Actors' perceptions of the forest as place, resource, and problem, and their understanding of changes within it, do not necessarily match, because of their differing scales of knowledge, and because of differing needs, interests, and values. Scale mismatch and scale politics in community forestry then result in a shift in power relations, the production of a new ecosystem, and the undermining of local knowledge systems (Nightingale 2003). That is, these shifts occur partly through the misunderstandings and conflicts produced out of entirely differently scaled, or partly overlapping scales of knowledge systems, but also from the ability of particular actors to mobilize different knowledge such as the global discourse on climate change and make knowledge claims for their own interests.

When we bring this analysis to climate change and programs like REDD+, it is clear scale politics pose some challenges for participatory CF. Decentralization of forest management is attributed with giving village users a greater sense of ownership and thus a willingness to ensure the long term viability of their forests. To sell this carbon on a global market, however, a mechanism is required that can bring together thousands of user groups into one package that can be marketed to a global buyer. A coalition of donor and civil society leaders are keen to see such a mechanism reflect the participatory, inclusive practices that have been institutionalized within community forestry, but exactly how to achieve that is far from obvious. Most user groups presently use annual assemblies of all members to deliberate key decisions, but the demands of a global carbon market will necessitate the formation of a core of elites who can act as an intermediary between the grassroots and national and international contexts. The proposals under consideration bring forest department staff as well as user groups and civil society representatives into such a forum. If we examine this issue in terms of scale politics, we see tremendous potential for local knowledge to be superseded by national and global understandings of climate change, as well as for local interests to be subsumed to sequester carbon. Unless scale mismatch is explicitly recognized, ambitions to include local knowledge in such negotiations, although laudable, are likely to ignore the multiple scales of knowledge within communities, and take partial and political claims to knowledge by elites as representative of local needs and interests.

\section{CONCLUSIONS}

Building from the discussions on scale dynamics, scale mismatch, and the political implications of choice of observational scale, we have theoretically developed the concept of 'knowledge scales' and illustrated it through empirical examples. We define scales of knowledge and argue that disparate scales of knowledge are an important scale mismatch, which together with scale politics lead to conflicts in Nepalese forest management. Our review of the literature shows the importance of clear and precise use of concepts, especially the distinction between scale and level, when we communicate between research fields.

Our discussion on scales of knowledge highlights an aspect of scale mismatch that has not been explored satisfactorily, and it questions simplistic assumptions about identifiable local knowledge systems that can be integrated into NRM and environmental assessments. We argue that although actors at various levels may have scale-dependent interests, the knowledge held by all actors is inherently multi-scalar. By conflating the level at which knowledge is expressed or mobilized with the scale of knowledge, researchers risk overlooking the differences within communities and between local knowledge systems, and thus fail to recognize the politics of scale, and knowledge, that result.

By exploring the mismatch between scales of knowledge held by actors in relation to each other and in relation to the forest ecosystem, we are able to explain how various actors perceive forest change differently, why there are struggles over the implementation of community forestry in Nepal, and why the expert position taken by researchers is not an objective or neutral one, but one of strategic interest for actors involved in 
forestry and for resulting policy making. Nepalese forests and forestry have undergone rapid changes since the 1980s, and one way to explain this is by saying that the social and ecological systems have not aligned properly, resulting in scale mismatch and disruption in the functions of the socialecological system (Cumming et al. 2006). However, whether the change is positive or negative depends on what functions are of interest, questions that are highly contested. The current promotion of so called expert knowledge by the DFO is strategically used by local elites to assert control over forest resources, leading to ecosystem change, a redefinition of the forest as a source of timber rather than a multiuse forest for local livelihoods and places of meaning, gradual disappearance of local knowledge, and changes in people's access to the forest and forest resources.

The use of mixed methods and data sets with different observational scales helped reveal how the forest signifies different things to the actors involved, but it also helped illustrate how these differences came about. We want to emphasize that such an understanding can only emerge by taking the epistemological position of situated, political, and partial knowledge, which turns the eye on the researcher and her or his underlying assumptions about the world. Instead of seeking a coherent view of reality, the position allows us to explore the gaps between worldviews. By using mixed methods, the incompatibilities between data sets become evident. When we scrutinize these gaps from a scale perspective, it becomes clear how these data sets, and knowledge held by actors, are based on different temporal and spatial scales, influencing the delineation of the forest as associated value, and as problem, creating multiple stories of forest change. This is particularly important because acknowledging multiple and divergent stories has policy implications. It requires a different organization of the NRM process, one which can allow open dialogue among actors without striving for a single dominant story as output.

From an epistemological perspective the consequence is also that the dominant story pushes out other knowledge systems, thereby decreasing the diversity of scales of knowledge, i.e., knowledge at a variety of scales held by local actors with direct relationships to the forest is ignored. In the long term it runs the risk of being forgotten, because some scales of observation are given precedence on the basis of being scientific, but also because ecological change and forestry practices focused on timber production can change people's relation to the forest, who has access to the forest, and in what ways.

Although efforts to integrate local and scientific knowledge are laudable, such integration requires caution and questioning of the improper applications of science to new contexts as well as an interrogation of how different knowledge systems may be fundamentally embedded in different scales, influencing problem definition and solutions. Local traditional knowledge is contextual and applied, which also means that it is diverse and inherently multiscalar, just as scientific knowledge is similarly diverse and multiscalar. Scale politics and mismatch between scales of knowledge exist within local communities, meaning that scientific knowledge will necessarily intersect politically as well as epistemologically with local knowledge. It is not simply the case that one needs to confer with local elites or those considered local experts, rather one needs to attend to how scales of knowledge produce a politics of knowing that can have real implications for on-the-ground management.

The approaches by scientists and donors to these questions are crucial because the choice of observational scale is part of creating preferential rights of interpretation and giving legitimacy to certain actors and perspectives. Attention to mismatch between knowledge scales is an important challenge for NRM that aims at bottom-up development and empowerment of marginalized groups. The objectives of such programs are potentially undermined by scale politics and scale mismatch such that forests are not managed well, the poorest of the poor do not benefit adequately, and livelihood benefits are compromised.

Responses to this article can be read online at: http://www.ecologyandsociety.org/issues/responses. php/5171

\section{Acknowledgments:}

We would like to thank Sverker Jagers at Göteborg University for great support throughout the working process, and also Sverker Molander and Björn Sandén at Chalmers University of Technology for their comments on earlier versions, which have helped improve the argument. Thanks to your interest in the topic the intellectual process has been very rewarding. Part of the research has been financially supported by Stiftelsen Futura. Three anonymous reviewers provided very constructive comments that improved the paper, any errors that remain are our own. We are also grateful to the Livelihoods and Forestry Programme in Nepal for generously sharing 'voices from the field' and offering insights into community forestry issues through our interactions. We would also like to thank Hemant Ojha, Peter Branney, Vijay Shrestha, Bharat Pokarel, Dinesh Paudel, Naya Sharma Paudel, Ramu Subedi, Pushpa Hamal, and the people of Mugu District for their insights, friendship, and tolerance for endless research discussions. The field work was supported by a FulbrightHays Doctoral Dissertation Award and by the National Science Foundation under Grant No. 9900788; in addition it was supported by the MacArthur Program on Global Change, Sustainability, and Justice, the Graduate School and the Department of Geography at the University of Minnesota. 


\section{LITERATURE CITED}

Agrawal, A. 1995. Dismantling the divide between indigenous and scientific knowledge. Development and Change 26:413-439.

Agrawal, A. 2002. Indigenous knowledge and the politics of classification. International Social Science Journal 54:287-297. http://dx.doi.org/10.1111/1468-2451.00382

Allen, T.F.H. 1998. The landscape "level" is dead: persuading the family to take it off the respirator. In D. L. Peterson and V. T. Parker, editors. Ecological scale. Theory and applications. Columbia University Press, New York, New York, USA.

Allen, C. R., and C. S. Holling. 2010. Novelty, adaptive capacity, and resilience. Ecology and Society 15(3): 24. [online] URL: http://www.ecologyandsociety.org/vol15/ iss3/art24/

Barnes, B., and D. Bloor. 1982. Relativism, rationalism, and the sociology of knowledge. In M. Hollis and S. Lukes, editors. Rationality and relativism. MIT Press, Cambridge, Massachusetts, USA.

Bassett, T. J., and K. B. Zuéli. 2000. Environmental discourses and the Ivorian Savanna. Annals of the Association of American Geographers 90:67-95. http://dx.doi. org/10.1111/0004-5608.00184

Berger, J. 1972. Ways of seeing. Penguin, London, UK.

Berkes, F., and C. Folke. 1998. Linking social and ecological systems for resilience and sustainability. Pages 1-26 in F. Berkes and C. Folke, editors. Linking social and ecological systems: management practices and social mechanisms for building resilience. Cambridge University Press, Cambridge, UK.

Buizer, M., B. Arts, and K. Kok. 2011. Governance, scale, and the environment: the importance of recognizing knowledge claims in transdisciplinary arenas. Ecology and Society 16(1): 21. [online] URL: http://www.ecologyandsociety.org/vol16/ iss $1 / \operatorname{art} 21 /$

Cash, D. W., W. N. Adger, F. Berkes, P. Garden, L. Lebel, P. Olsson, L. Pritchard, and O. Young. 2006. Scale and crossscale dynamics: governance and information in a multilevel world. Ecology and Society 11(2): 8. [online] URL: http:// www.ecologyandsociety.org/vol11/iss2/art8/

Cumming, G. S., D. H. M. Cumming, and C. L. Redman. 2006. Scale mismatch in social-ecological systems: causes, consequences, and solutions. Ecology and Society 11(1): 14. [online] URL: http://www.ecologyandsociety.org/vol11/iss1/ $\underline{\operatorname{art} 14 /}$

Duan, K., T. Yao, and L. G. Thompson. 2006. Response of monsoon precipitation in the Himalayas to global warming.
Journal of Geophysical Research 111, D19110. http://dx.doi. org/10.1029/2006JD007084

Folke, C. 2006. Resilience: the emergence of a perspective for social-ecological systems analyses. Global Environmental Change 16:253-267. http://dx.doi.org/10.1016/j.

gloenvcha.2006.04.002

Foucault, M. 1980. Power/knowledge: selected interviews and other writings, 1972-1977. Pantheon Books, New York, New York, USA.

Gagnon, C. A., and D. Berteaux. 2009. Integrating traditional ecological knowledge and ecological science: a question of scale. Ecology and Society 14(2): 19. [online] URL: http:// www.ecologyandsociety.org/vol14/iss2/art19/

Gibson, C. C., E. Ostrom, and T. K. Ahn. 2000. The concept of scale and the human dimensions of global change: a survey. Ecological Economics 32:217-239. http://dx.doi.org/10.1016/ S0921-8009(99)00092-0

Government of Nepal. 1995. Forest Act 1993 and Forest Regulations 1995. Ministry of Forest and Soil Conservation. Government of Nepal, Kathmandu, Nepal.

Haraway, D. 1991. Simians, cyborgs, and women: the reinvention of nature. Routledge, New York, New York, USA.

Herod, A., and M. W. Wright. 2002. Geographies of power: placing scale. Blackwell, Oxford, UK.

Hulme, M. 2010. Problems with making and governing global kinds of knowledge. Global Environmental Change 20:558-564. http://dx.doi.org/10.1016/j.gloenvcha.2010.07.005

Huntington, H. P., R. S. Suydam, and D. H. Rosenberg. 2004. Traditional knowledge and satellite tracking as complementary approaches to ecological understanding. Environmental Conservation 31:177-180. http://dx.doi.org/10.1017/ S0376892904001559

Khadka, M. 2010. Why does exclusion continue in Nepal's community forestry? Aid, knowledge and power in forest policy process. Lambert Academic, Saarbrücken, Germany.

Kuhn, T. 1962/1970. The structure of scientific revolutions. Second edition. University of Chicago Press, Chicago, Illinois, USA.

Latour, B. 1987. Science in action. Harvard University Press, Cambridge, Massachusetts, USA.

Lebel, L. 2006. The politics of scale in environmental assessments. Pages 37-57 in W. V. Reid, F. Berkes, T. J. Wilbanks, and D. Capistrano, editors. Bridging scales and knowledge systems. Concepts and applications in ecosystem assessment. Island Press, Washington, D.C., USA. 
Levin, S. A. 1992. The problem of pattern and scale in ecology: the Robert H. MacArthur award lecture. Ecology 73:1943-1967. [online] URL: http://www.jstor.org/stable/1941447 http://dx.doi.org/10.2307/1941447

Lewontin, R. C. 1991. Facts and the factitious in the natural sciences. Critical Inquiry 18:140-153. http://dx.doi. org/10.1086/448627

Livingstone, D. N., and C. W. J. Withers. 1999. Geography and enlightenment. University of Chicago Press, Chicago, Illinois, USA.

Longino, H. E. 1990. Science as social knowledge: values and objectivity in scientific inquiry. Princeton University Press, Princeton, New Jersey, USA.

Millennium Ecosystem Assessment (MEA). 2005. Ecosystems and human wellbeing. Multiscale assessments, volume 4. Findings of the Sub-global Assessment Working Group of the Millennium Ecosystem Assessment. Island press, Washington, D.C., USA.

Manson, S. M. 2008. Does scale exist? An epistemological scale continuum for complex human-environment systems. Geoforum 39:776-788. http://dx.doi.org/10.1016/j. geoforum.2006.09.010

Nightingale, A. J. 2001. A 'trialectic' of community forestry management in Mugu District, Western Nepal: power, cultural meanings and ecology. Dissertation. Geography Department, University of Minnesota, Minneapolis, Minnesota, USA.

Nightingale, A. J. 2003. A feminist in the forest: situated knowledges and mixing methods in natural resource management. ACME 2:77-90.

Nightingale, A. J. 2005. 'The experts taught us all we know': professionalisation and knowledge in Nepalese community forestry. Antipode 37:581-604. http://dx.doi.org/10.1111/ j.0066-4812.2005.00512.x

Nightingale, A. J. 2006. The nature of gender: work, gender, and environment. Environment and Planning D: Society and Space 24:165-185. http://dx.doi.org/10.1068/d01k

Nightingale, A. J. 2010. A forest community or community forestry? Beliefs, meanings and nature in north-western Nepal. Pages 196-240 in A. Guneratne, editor. Under the roof of the world: critical Himalayan environments. Routledge, London, UK.

O'Flaherty, M. R., I. J. Davidson-Hunt, and M. Manseau. 2008. Indigenous knowledge and values in planning for sustainable forestry: Pikangikum First Nation and the Whitefeather Forest Initiative. Ecology and Society 13(1): 6. [online] URL: http://www.ecologyandsociety.org/vol13/iss1/ art6/
Ojha, H. R. 2008. Reframing governance: understanding deliberative politics in Nepal's Terai forestry. Adroit, New Delhi, India.

Ojha, H. R., N. Timsina, C. Kumar, B. Belcher, and M. Banjade. 2008. Communities, forests and governance: policy and institutional innovations from Nepal. Adroit, New Delhi, India.

O'Neill, R. V., and A. W. King. 1998. Homage to St. Michael; or, why are there so many books on scale? Pages 3-16 in D. L. Peterson and V. T. Parker, editors. Ecological scale. Theory and applications. Columbia University Press, New York, New York, USA.

Ostrom, E. 2009. A general framework for analyzing sustainability of social-ecological systems. Science 325:419-422. http://dx.doi.org/10.1126/science.1172133

Papaik, M. J., B. Sturtevant, and C. Messier. 2008. Crossing scales and disciplines to achieve forest sustainability. Ecology and Society 13(1): 30. [online] URL: http://www. ecologyandsociety.org/vol13/iss1/art30/

Peterson, D. L., and V. T. Parker, editors. 1998. Ecological scale. Theory and applications. Columbia University Press, New York, New York, USA.

Rangan, H., and C. A. Kull. 2009. What makes ecology 'political'?: rethinking 'scale' in political ecology. Progress in Human Geography 33:28-45. http://dx.doi.org/10.1177/030$\underline{9132508090215}$

Reid, W. V., F. Berkes, T. J. Wilbanks, and D. Capistrano, editors. 2006. Bridging scales and knowledge systems. Concepts and applications in ecosystem assessment. Island Press, Washington, D.C., USA.

Rocheleau, D. 1995. Maps, numbers, text, and context: mixing methods in feminist political ecology. Professional Geographer 47:458-466. http://dx.doi.org/10.1111/ j.0033-0124.1995.00458.x

Sheppard, E., and R. McMaster, editors. 2003. Scale and geographic inquiry: nature, society, and method. WileyBlackwell, Oxford, UK.

Shrestha, M. L., S. P. Joshi, U. R. Bhuju, D. B. Joshi, and M. Gautam. 1995. Community forestry manual. HMG Ministry of Forests and Soils Conservation, Kathmandu, Nepal.

St. Martin, K. 2005. Mapping economic diversity in the First World: the case of fisheries. Environment and Planning A 37:959-979. http://dx.doi.org/10.1068/a36296

Termeer, C. J. A. M., A. Dewulf, and M. van Lieshout. 2010. Disentangling scale approaches in governance research: comparing monocentric, multilevel, and adaptive governance. 
Ecology and Society 15(4): 29. [online] URL: http://www. ecologyandsociety.org/vol15/iss4/art29/

Thoms, C. A. 2008. Community control of resources and the challenge of improving local livelihoods: a critical examination of community forestry in Nepal. Geoforum 39:1452-1465. http://dx.doi.org/10.1016/j.geoforum.2008.01.006

van Lieshout, M., A. Dewulf, N. Aarts, and C. Termeer. 2011. Do scale frames matter? Scale frame mismatches in the decision making process of a "mega farm" in a small Dutch village. Ecology and Society 16(1): 38. [online] URL: http:// www.ecologyandsociety.org/vol16/iss1/art38/

Wilbanks, T. J. 2006. How scale matters: some concepts and findings. Pages 21-35 in W. V. Reid, F. Berkes, T. J. Wilbanks, and D. Capistrano, editors. Bridging scales and knowledge systems. Concepts and applications in ecosystem assessment. Island Press, Washington, D.C., USA.

Xu, J., R. E. Grumbine, A. Shrestha, M. Eriksson, X. Yang, Y. Wang, and A. Wilkes. 2009. The melting Himalayas: cascading effects of climate change on water, biodiversity, and livelihoods. Conservation Biology 23:520-530. http://dx. doi.org/10.1111/j.1523-1739.2009.01237.x

Zimmerer, K. S. 2000. The reworking of conservation geographies: nonequilibrium landscapes and nature-society hybrids. Annals of the Association of American Geographers 90:356-369. http://dx.doi.org/10.1111/0004-5608.00199 